\title{
Rift Valley fever virus subunit vaccines confer complete protection against a lethal virus challenge
}

\author{
S.M. de Boer ${ }^{\mathrm{a}, \mathrm{b}, 1}$, J. Kortekaas $^{\mathrm{a}}$, A.F. Antonis ${ }^{\mathrm{a}}$, J. Kant ${ }^{\mathrm{a}}$, J.L. van Oploo ${ }^{\mathrm{b}}$, P.J.M. Rottier ${ }^{\mathrm{b}}$, \\ R.J.M. Moormann ${ }^{\mathrm{a}, \mathrm{b}, *}$, B.J. Bosch ${ }^{\mathrm{b}}$ \\ a Central Veterinary Institute of Wageningen University and Research Centre, Cluster of Mammalian Virology, Edelhertweg 15, 8219 PH, Lelystad, The Netherlands \\ ${ }^{\mathrm{b}}$ Department of Infectious Diseases and Immunology, Virology Division, Faculty of Veterinary Medicine, Utrecht University, Yalelaan 1, 3584 CL, Utrecht, The Netherlands
}

\section{A R T I C L E I N F O}

\section{Article history:}

Received 21 September 2009

Received in revised form 8 December 2009

Accepted 23 December 2009

Available online 5 January 2010

\section{Keywords:}

Rift Valley fever virus

Virus-like particle

VLP

Subunit vaccine

DIVA

\begin{abstract}
A B S T R A C T
Rift Valley fever virus (RVFV) is an emerging mosquito-borne virus causing significant morbidity and mortality in livestock and humans. Rift Valley fever is endemic in Africa, but also outside this continent outbreaks have been reported. Here we report the evaluation of two vaccine candidates based on the viral Gn and Gc envelope glycoproteins, both produced in a Drosophila insect cell expression system. Virus-like particles (VLPs) were generated by merely expressing the Gn and Gc glycoproteins. In addition, a soluble form of the Gn ectodomain was expressed and affinity-purified from the insect cell culture supernatant. Both vaccine candidates fully protected mice from a lethal challenge with RVFV. Importantly, absence of the nucleocapsid protein in either vaccine candidate facilitates the differentiation between infected and vaccinated animals using a commercial recombinant nucleocapsid protein-based indirect ELISA.
\end{abstract}

(c) 2010 Elsevier Ltd. All rights reserved.

\section{Introduction}

Rift Valley fever virus (RVFV) is a mosquito-borne zoonotic virus that causes recurrent and massive outbreaks affecting humans and ruminants. The virus is endemic in Africa and emerged in Saudi Arabia and Yemen in 2000 [1]. Sheep, goat and cattle are the main species affected during a RVFV outbreak. Abortion storms and high newborn fatality rates, which can approach $100 \%$, are typical features of such outbreaks $[2,3]$. The virus can be transmitted to humans via direct contact with infected animal tissues and by the bites of infected mosquitoes. Disease in humans is generally mild consisting of fever, myalgia, headache and photophobia [3]. A small percentage of infected individuals, however, develop more severe symptoms like retinitis, retinal lesions, hepatitis or hemorrhagic fever $[3,4]$. Although the overall case-fatality rate is estimated at $0.5-1.0 \%$ [5], recent outbreaks show considerably higher numbers [6-8]. The high case-fatality rates combined with the potential of rapid spread via its vector explains the recognition of RVFV as a potential bioterrorism agent by the United States government $[9,10]$. Given the impact of RVF outbreaks on livestock, the human

\footnotetext{
* Corresponding author. Room 0.18.022, Edelhertweg 15, 8219 PH, Lelystad, The Netherlands. Tel.: +31 0320238242.

E-mail addresses: matthijn.deboer@wur.nl (S.M. de Boer), rob.moormann@wur.nl (R.J.M. Moormann).

${ }^{1}$ Tel. +310320 238198 .
}

population, and the economy, there is an urgent need for a safe and effective vaccine.

RVFV is a member of the Phlebovirus genus within the Bunyaviridae family. The virus is membrane-enveloped and contains a segmented negative-sense genome. The three genome segments are called $\mathrm{L}, \mathrm{M}$ and $\mathrm{S}$ referring to the large, medium and small segment. The L segment encodes the viral polymerase. The S segment is of ambisense polarity and codes for the non-structural protein NSs in sense polarity and the nucleocapsid protein $(\mathrm{N})$ in antisense polarity [11]. The M segment encodes the two surface glycoproteins Gn and Gc, and the two non-structural proteins NSm1 and NSm2. $\mathrm{Gn}(\sim 54 \mathrm{kDa})$ and $\mathrm{Gc}(\sim 59 \mathrm{kDa})$ [12] form a heterodimer after processing of the polyprotein by host proteases in the endoplasmic reticulum (ER) [13]. The Gc glycoprotein harbours a C-terminal lysine-based ER retention signal whereas the $\mathrm{Gn}$ protein contains a C-terminal Golgi localization signal. Heterodimerization of Gn and $\mathrm{Gc}$ is thus required for the transport of Gc to the Golgi compartment, where virus assembly takes place [14]. According to a $\mathrm{T}=12$ icosahedral symmetry [15], RVFV incorporates $720 \mathrm{Gn}-\mathrm{Gc}$ heterodimers into its envelope, which function in virus binding to and entry into cells [13].

Over the years, much effort has been put forth developing RVFV vaccines using various strategies, including subunit [16-18], DNA [19,20], virus vector-based [21,22], live-attenuated virus [23-27] and inactivated whole virus vaccines [28] (for a recent review see [29]). This work provided considerable evidence that humoral immunity is sufficient for protection against RVFV. The Gn and Gc 
glycoproteins are supposed to be crucial for generating a protective humoral immune response.

The production of a RVFV vaccine outside endemic areas must be safe, preferably without the need for a high biosafety containment facility. In addition, animal transport regulations require that the vaccine enables the differentiation between infected and vaccinated animals (DIVA) using a field validated diagnostic test. Viral subunit vaccines are safe for the environment, since neither production nor vaccination involves a replicating virus. Virus-like particles (VLPs) can be used as a special type of viral subunit vaccine, mimicking the overall virus structure, thus preserving the antigenicity of the authentic virus [30,31].

VLPs have been successfully produced for different members of the Bunyaviridae family including Uukuniemi virus (UUKV), Hantaan (HTN) virus and RVFV $[18,32,33]$. Whereas expression of HTN virus VLPs was described to depend on the presence of the N protein [34], UUKV and RVFV VLPs can be produced by expressing only the Gn and Gc glycoproteins [18,35]. Vaccination of mice with RVFV VLPs containing the N protein provided $90 \%$ [17] or $56 \%$ [18] protection upon RVFV challenge after three immunizations. In the latter study, vaccination with VLPs without the N protein, however provided only $19 \%$ protection [18].

Here, we have generated RVFV VLPs comprising only the Gn and Gc protein using a robust Drosophila insect protein expression system. Since studies have indicated that antibodies to $\mathrm{Gn}$ alone are sufficient for virus neutralization [16,21] we compared the vaccine efficacy of VLPs - with or without adjuvant - with that of adjuvanted, purified Gn ectodomain using a mouse infection model. All vaccine candidates formulated with adjuvant provided full protection against a lethal RVFV challenge. Contrary to a recent report [18], vaccination with VLPs lacking the $\mathrm{N}$ protein also provided $100 \%$ protection, even without adjuvant. The absence of the $\mathrm{N}$ protein in all vaccine preparations facilitates the development of a safe and highly effective RVFV DIVA vaccine for use in livestock.

\section{Materials and methods}

\subsection{Virus and cells}

The RVFV strain M35/74 was kindly provided by Prof. Dr. Janusz Paweska of the National Institute for Communicable Diseases (Johannesburg, South Africa) and Dr. Christiaan Potgieter of the Agricultural Research Council-Onderstepoort Veterinary Institute (ARC-OVI, Onderstepoort, South Africa). The virus was handled under BSL-3 laboratory conditions in biosafety class III glove boxes. Virus stocks were produced by infection of BHK-21 cells grown on $\mathrm{CO}_{2}$-independent medium (GIBCO ${ }^{\mathrm{TM}}$, Carlsbad, CA, USA) supplemented with $100 \mathrm{U} / \mathrm{ml}$ penicillin, $100 \mu \mathrm{g} / \mathrm{ml}$ streptomycin (GIBCO), $2 \mathrm{mM} \mathrm{L}$-glutamine (GIBCO) and $5 \%$ fetal calf serum (FCS) at $37^{\circ} \mathrm{C}$. Virus stocks were titrated on BHK-21 cells using 6-fold dilutions. Titres are depicted as 50\% tissue culture infectious doses $\left(\mathrm{TCID}_{50}\right)$.

\subsection{Plasmid construction}

The GnGc-coding sequence of the M segment of RVFV strain M35/74, codon optimized for optimal expression in human and insect cells, was synthesized by the GenScript cooperation (Piscataway, NJ, USA). For expression of the GnGc gene and the gene encoding the $\mathrm{Gn}$ ectodomain ( $\mathrm{Gn}-\mathrm{e})$, the insect expression vector pMT/BiP/V5-HisA (Invitrogen ${ }^{\mathrm{TM}}$, Carlsbad, CA, USA) was used, which contains an inducible metallothionein (MT) promoter and the Drosophila BiP secretion signal. The sequences to be expressed were cloned into the $\mathrm{pMT} / \mathrm{BiP} / \mathrm{V} 5-\mathrm{His}$ A vector, yielding plasmids pMT-GnGc and pMT-Gn-e. In both, the sequence encoding the Gn signal peptide was replaced by that coding for the BiP signal peptide, specifying the junction sequence "GLSLG-RSL-
$A E D P H "$ (BiP, linker, Gn ectodomain). In the pMT-Gn-e plasmid, the $\mathrm{Gn}$ ectodomain sequence was extended $3^{\prime}$ terminally to add a C-terminal 6xHis-tag to the protein as follows: "YQCHT-DPTG$H H H H H H^{\prime}$ junction (Gn-e-linker-His tag). To allow expression in mammalian cells, the codon-optimized GnGc gene was cloned into the pCAGGS expression vector [36], yielding pCAGGS-GnGc.

For the quantification of $\mathrm{Gn}$ and $\mathrm{Gc}$ glycoproteins by quantitative Western blot analysis, a DNA fragment was synthesized (GenScript) that encodes two previously described linear epitopes of $\mathrm{Gn}$ (residues 374-CFEHKGQYKGTMDSGQTKRE-393) and Gc (residues 975-VFERGSLPQTRNDKTFAASK-994) [37]. The synthesized DNA fragment, containing an upstream BamHI site and a downstream EcoRI site, was ligated into the BamHI/EcoRI site of the pGEX-2T bacterial expression vector (GE Healthcare, Diegem, Belgium) in frame with the glutathione $S$-transferase (GST) gene, yielding the pGEX-GnGc plasmid. All constructs were verified by DNA sequencing (Baseclear, Leiden, The Netherlands).

\subsection{Expression and purification of RVFV VLPs and the Gn ectodomain}

The pMT-GnGc and pMT-Gn-e constructs were each cotransfected into Drosophila Schneider (S2) cells [38,39] at a ratio of 19:1 with the Blasticidin resistance vector pCoBlast (Invitrogen ${ }^{\mathrm{TM}}$ ) according to manufacturers' recommendations. Stably transformed cells were selected by growth at $27^{\circ} \mathrm{C}$ in serum-free InsectXpress medium (Lonza, Westburg, Leusden, The Netherlands) containing $25 \mu \mathrm{g} / \mathrm{ml}$ Blasticidin-S- $\mathrm{HCl}$ (Invitrogen ${ }^{\mathrm{TM}}$ ) and maintained in this culture medium in the presence of $10 \mu \mathrm{g} / \mathrm{ml}$ Blasticidin-S-HCl. For protein expression, these stable cell lines were seeded at a density of $1.5 \times 10^{6}$ cells $/ \mathrm{ml}$ and induced by addition of cupper sulphate $(500 \mu \mathrm{M})$ to the culture medium. Ten days later RVFV VLPs were purified from the pre-cleared $\left(10,000 \times \mathrm{g}, 20 \mathrm{~min}, 4^{\circ} \mathrm{C}\right)$ culture supernatant by sedimentation through a sucrose cushion. Typically, $32 \mathrm{ml}$ of pre-cleared supernatant was placed on top of $4 \mathrm{ml} \mathrm{20 \%}$ (wt/wt) sucrose in TN buffer (10 mM Tris pH 7.4, $100 \mathrm{mM}$ $\mathrm{NaCl}$ ) and centrifuged for $2 \mathrm{~h}$ at $100,000 \times \mathrm{g}$ at $4{ }^{\circ} \mathrm{C}$ in a Beckman SW32Ti rotor. The pellet was dissolved in $100 \mu \mathrm{l}$ TN buffer on ice. For flotation experiments, concentrated VLPs were mixed with a TN-buffered $60 \%$ sucrose solution (total volume $1.4 \mathrm{ml}$ ) and used as the bottom layer of a discontinuous sucrose gradient. Layers of 50 , 40,30 and $20 \%$ (wt/wt) sucrose, of each $0.9 \mathrm{ml}$, were placed on top, respectively. After a $72 \mathrm{~h}$ spin at $160,000 \times g$ at $4{ }^{\circ} \mathrm{C}$ in a Beckman SW55Ti rotor, $0.5 \mathrm{ml}$ fractions were collected. The sucrose densities were determined and all fractions were analyzed by sodium dodecyl sulfate polyacrylamide gel electrophoresis (SDS-PAGE) and Western blotting for the presence of RVFV glycoproteins.

The secreted Gn ectodomain was purified from the cell culture supernatant by virtue of its C-terminal 6xHis-tag using ProBond ${ }^{\mathrm{TM}}$ nickel-chelating resin according to the manufacturer's recommendations (Invitrogen ${ }^{\mathrm{TM}}$ ). The Gn-e protein was eluted from the washed beads with $250 \mathrm{mM}$ imidazole (Sigma) and concentrated using an Amicon ${ }^{\circledR}$ Ultra-4 concentrator with a molecular mass cutoff of $30 \mathrm{kDa}$ (Milipore ${ }^{\mathrm{TM}}$, Billerica, MA, USA).

\subsection{Expression and purification of GST-GnGc}

The GST-GnGc fusion protein was expressed and purified essentially as described before [40]. Briefly, BL21 cells (Novagen, Gibbstown, NJ, USA), transformed with the pGEX-GnGc plasmid, were grown in $2 \times$ yeast-tryptone medium to log phase and subsequently induced by adding isopropyl- $\beta$-D-thiogalactopyranoside to a final concentration of $0.5 \mathrm{mM}$. Three hours later, the cells were pelleted, resuspended in $1 / 25$ volume of $10 \mathrm{mM}$ Tris $(\mathrm{pH}$ 8.0), $10 \mathrm{mM}$ EDTA, $1 \mathrm{mM}$ phenylmethylsulfonyl fluoride, and sonicated on ice. The cell homogenate was centrifuged at $1600 \times g$ 
(JA-10 rotor) for $30 \mathrm{~min}$ at $4{ }^{\circ} \mathrm{C}$. To each $50 \mathrm{ml}$ of supernatant, $2 \mathrm{ml}$ of glutathione-Sepharose 4B (GE Healthcare, 50\% [vol/vol] in phosphate-buffered saline [PBS]) was added, and the mixture was incubated overnight at $4{ }^{\circ} \mathrm{C}$ under rotation. The beads were washed three times with $50 \mathrm{ml}$ of PBS and resuspended in a final volume of $1 \mathrm{ml}$ PBS. Purified GST-GnGc was eluted from the beads with $10 \mathrm{mM}$ glutathione in PBS. The purity and concentration of the purified GST-GnGc protein was determined by gel electrophoresis followed by Coomassie staining and by Nanodrop1000 (Wilmington, DE, USA) measurements, respectively (data not shown).

\subsection{Western blotting}

Proteins were separated in 10\% SDS-PAGE gels (Biorad system) and subsequently transferred to polyvinylidene fluoride (PVDF) membranes (Biorad). After blocking, the blots were incubated with rabbit polyclonal antisera raised against peptides derived from the Gn or the Gc protein (GenScript, Piscataway, NJ, USA). The Gn antiserum $(\alpha-\mathrm{Gn})$ was raised against a synthetic peptide comprising residues 374-CFEHKGQYKGTMDSGQTKRE-393. For obtaining the Gc antiserum ( $\alpha-\mathrm{Gc})$ a peptide comprising residues 975VFERGSLPQTRNDKTFAASK-994 was used [37]. Goat anti-rabbit horseradish peroxidase-conjugate (Biorad) was used as the secondary antibody and protein detection was performed using the Amersham ECL ${ }^{\mathrm{TM}}$ Western blotting detection reagents (GE Healthcare). Protein quantification of $\mathrm{Gn}$ and $\mathrm{Gc}$ was performed by quantitative Western blotting using a two-fold serial dilution of the purified GST-GnGc fusion protein as a calibration marker (data not shown).

\subsection{Vaccination and challenge of mice}

Female BALB/c mice (Charles River laboratories, Maastricht, The Netherlands) were housed in groups of five animals in type III filtertop cages and kept under BSL-3 conditions. The light regime was set at $14 \mathrm{~h} \mathrm{light} / 10 \mathrm{~h}$ dark, the temperature at $22^{\circ} \mathrm{C}$ and the relative humidity at 55\%. Food and water was provided ad libitum. Groups of ten 7-week-old mice were vaccinated via the intraperitoneal route on day 0 with saline, Gn-e protein $(10 \mu \mathrm{g} / \mathrm{mice})$ or VLPs $(10 \mu \mathrm{g} /$ mice $)$ formulated in Stimune, a water-in-oil adjuvant (Prionics, Lelystad, The Netherlands) [41], in a total volume of $500 \mu \mathrm{l}$. Two additional groups of ten mice were either vaccinated intraperitoneally with non-adjuvanted VLPs $(10 \mu \mathrm{g} /$ mice $)$ or were left untreated (non-vaccinated). We daily monitored for clinical signs and measured body weights of the mice every week. Blood samples, to be used for serological tests, were obtained from the tail vein at different time points. All groups were boosted on day 21 , performed in the same way as the initial immunization. On day 42 , all mice were challenged via the intraperitoneal route with $10^{2.7} \mathrm{TCID}_{50}$ of RVFV strain M35/74 in $0.5 \mathrm{ml}$ culture medium. This optimal challenge dose, for intraperitoneal inoculation, was determined by two independent dose titration studies, performed with 7 and 11-week-old female BALB/c mice (Antonis AF et al., manuscript in preparation). Challenged mice were monitored daily for visual signs of illness and mortality. At day 62 post-initial immunization, all animals that survived the RVFV challenge were bled via orbital puncture under general anaesthesia using xylazine $(7 \mathrm{mg} / \mathrm{kg})$ and ketamine $(70 \mathrm{mg} / \mathrm{kg})$ and euthanized by cervical dislocation. This experiment was approved by the Ethics Committee for Animal Experiments of the Central Veterinary Institute of Wageningen UR.

\subsection{Analysis of the antisera by ELISA}

The commercial recN-ELISA was originally developed for analysis of sera from livestock [42]. For analysis of the mouse sera, the
ELISA was performed essentially according to the manufacturer's instructions (BDSL, Ayrshire Scotland, UK), but with the following modifications. Plates were coated with stock antigen, diluted 1:3000 and all mouse sera were analyzed in duplicate. As the secondary antibody, a peroxidase-conjugated rabbit anti-mouse antibody (DAKO, Glostrup, Denmark) was used. Optical densities were measured at $405 \mathrm{~nm}$ and the cut-off was arbitrarily set at 0.80 .

For the GnGc peptide ELISA, 96 well plates were coated overnight at $4{ }^{\circ} \mathrm{C}$ with GST-GnGc protein $(0.27 \mu \mathrm{g} /$ well $)$ comprising the previously described selected linear epitopes of Gn and Gc fused to the GST protein. Plates were subsequently blocked with $10 \%$ skimmed milk in PBS for $1 \mathrm{~h}$ at $37^{\circ} \mathrm{C}$. Mouse serum was diluted (1:16) in dilution buffer (PBS with $2 \%$ skimmed milk) and $50 \mu \mathrm{l}$ was added to the wells. After $1 \mathrm{~h}$ incubation at $37^{\circ} \mathrm{C}$ and three washes with wash buffer (PBS with 0.05\% Tween-20) incubation with a peroxidase-conjugated rabbit anti-mouse antibody (DAKO) was performed for $1 \mathrm{~h}$ at $37^{\circ} \mathrm{C}$. After three washing steps, $100 \mu \mathrm{l}$ of substrate buffer $(100 \mathrm{mM} \mathrm{NaAc} \mathrm{pH} 6.0)$ containing $0.1 \mathrm{mg} / \mathrm{ml}$ 3,3',5,5'-tetramethyl-benzidine (TMB, Sigma-Aldrich ${ }^{\mathrm{TM}}$, St. Louis, MO, USA) and $0.005 \% \mathrm{H}_{2} \mathrm{O}_{2}$ was added. After 30 min incubation at room temperature (RT), $50 \mu \mathrm{l} 0.5 \mathrm{M}$ sulphuric acid was added to each well. Optical densities were measured at $450 \mathrm{~nm}$.

\subsection{Virus neutralization tests}

Virus neutralization tests were performed under BSL-3 conditions using RVFV strain M35/74. Sera collected one day before the second immunization or challenge were pooled and analyzed in quadruplet. The serum pools were diluted (1:32) in $100 \mu \mathrm{l}$ $\mathrm{CO}_{2}$-independent medium (GIBCO), supplemented with $100 \mathrm{U} / \mathrm{ml}$ penicillin and $100 \mu \mathrm{g} / \mathrm{ml}$ streptomycin (GIBCO), L-glutamine $2 \mathrm{mM}$ (GIBCO) and 5\% FCS. Two-fold serial dilutions of the sera $(50 \mu \mathrm{l})$ were mixed in 96-well plates with $50 \mu \mathrm{l}$ of culture medium containing $\sim 150-250$ TCID $_{50}$ of RVFV. After $2.5 \mathrm{~h}$ incubation at RT, $50 \mu \mathrm{l}$ culture medium containing $4 \times 10^{4} \mathrm{BHK}-21$ cells was added to each well. After a 3-4 days incubation period at $37^{\circ} \mathrm{C}$, the cultures were scored for cytopathic effect. Fifty percent end point titres were calculated using the Spearman-Kärber method [43,44].

\subsection{Immunoperoxidase monolayer assay (IPMA)}

Monolayers of BHK-21 cells in 96 well plates were transfected with 100 ng of pCAGGS-GnGc using jetPEI ${ }^{\mathrm{TM}}$ according to manufacturers' instructions (Polyplus transfection, Illkirch, France). At $24 \mathrm{~h}$ after transfection, plates were washed with PBS and dried for $1 \mathrm{~h}$ at RT. Cells were disrupted via a freeze-thaw step at $-20^{\circ} \mathrm{C}$ and fixed with $4 \%$ paraformaldehyde for $10 \mathrm{~min}$ at RT. After three washes with PBS, mouse serum was added to the cells in a four-fold serial dilution in $100 \mu$ l block buffer ( $4 \%$ horse-serum, $0.5 \mathrm{M} \mathrm{NaCl}$, $1 \%$ Tween-80 and $0.1 \% \mathrm{NaN}_{3}$ ). The cells were washed three times with wash buffer (PBS with $0.15 \mathrm{M} \mathrm{NaCl}$ and $0.05 \%$ Tween-80), and subsequently incubated with peroxidase-conjugated rabbit antimouse antibodies (DAKO) diluted in conjugate buffer ( $4 \%$ horse serum, $0.5 \mathrm{M} \mathrm{NaCl}$ and $1 \%$ Tween-80) for $1 \mathrm{~h}$ at $37^{\circ} \mathrm{C}$. Cells were washed three times with wash buffer after which activity of peroxidase was detected using 3-amino-9-ethyl-carbazole (Sigma) as the substrate. Titres were calculated using the Spearman-Kärber method $[43,44]$.

\subsection{Quantitative real-time reverse-transcriptase PCR (qRRT-PCR)}

Livers and brains of deceased or euthanized mice were collected during the experiment. Autoclaved Zikonia beads $\sim 1.2 \mathrm{~g}$ (Zirconia $1.0 \mathrm{~mm}$ beads, Biospec) were mixed with $\sim 75 \mathrm{mg}$ of tissue and 
$600 \mu l$ lysis buffer (RNeasy mini kit, Qiagen). The tissue was disrupted by vortexing for $15 \mathrm{~min}$ before pelletation for $10 \mathrm{~min}$ at $7200 \times \mathrm{g}$. An eluate volume of $350 \mu \mathrm{l}$ was used to isolate total RNA using the Qiagen mini RNeasy kit according to the manufacturers' recommendations. The total RNA was eluted with $30 \mu$ l elution buffer of which $5 \mu \mathrm{l}$ was used for analysis by qRRT-PCR as described [45].

\subsection{Transmission electron microscopy (TEM)}

RVFV VLPs present in the clarified $\left(10,000 \times g, 20 \mathrm{~min}, 4^{\circ} \mathrm{C}\right) \mathrm{S} 2$ cell culture supernatant were fixed $\left(10 \mathrm{~min}, 4^{\circ} \mathrm{C}, 0.5 \%\right.$ glutaralde- hyde [Polysciences, Warrington, PA, USA] in $0.5 \mathrm{mM}$ phosphate buffer $\mathrm{pH} 7)$ and purified by sedimentation $\left(1.5 \mathrm{~h}, 4^{\circ} \mathrm{C}, 100,000 \times \mathrm{g}\right)$ through a $28 \%(\mathrm{w} / \mathrm{v})$ sucrose cushion onto a $45 \%(\mathrm{w} / \mathrm{v})$ sucrose cushion. The collected interphase was diluted using distilled water and spun $\left(1.5 \mathrm{~h}, 4{ }^{\circ} \mathrm{C}, 100,000 \times \mathrm{g}\right)$ onto a $45 \%(\mathrm{w} / \mathrm{v})$ sucrose cushion. The VLP fraction which settled on top of the $45 \%(\mathrm{w} / \mathrm{v})$ sucrose was applied to copper Formvar-carbon coated grids (Stork Veco BV, Eerbeek, The Netherlands). The VLP-coated grids were stained with $1 \%$ or $2 \%$ sodium phosphotungstate $\mathrm{pH} 7$ (Merck, Darmstadt, Germany). Images were recorded at a calibrated magnification of 60,000× using a Jeol 1010 electron microscope.

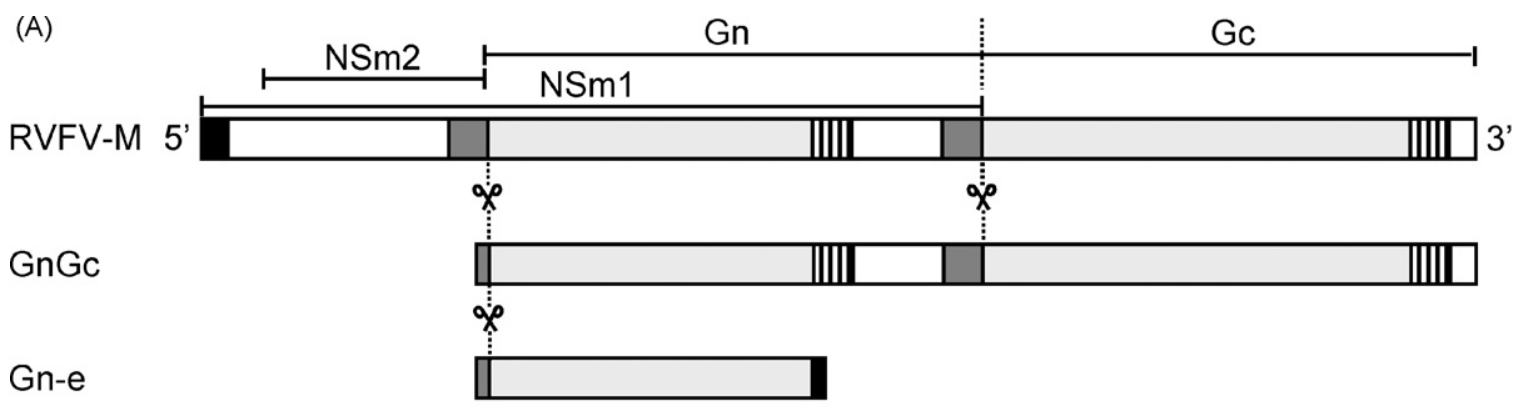

(B)
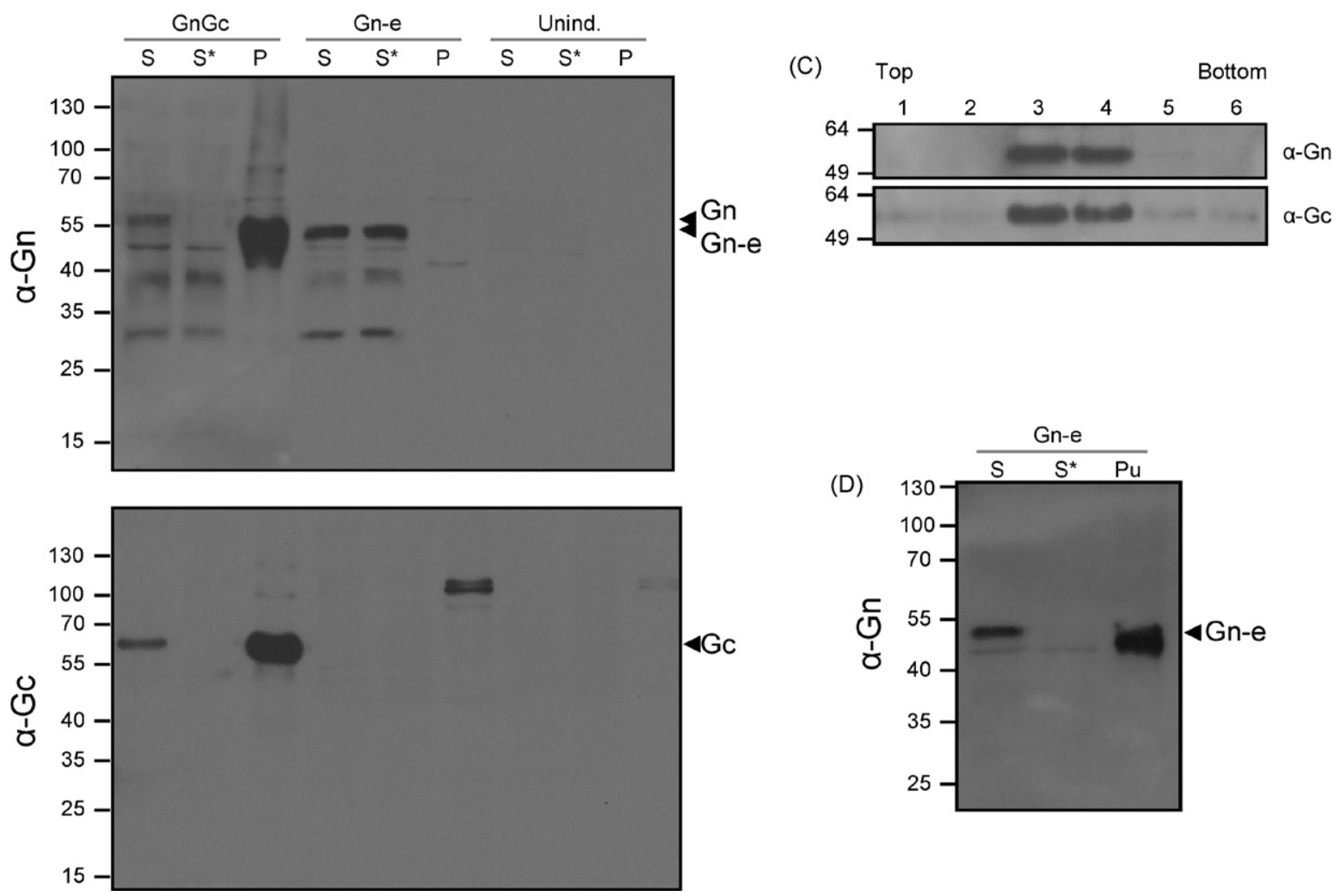

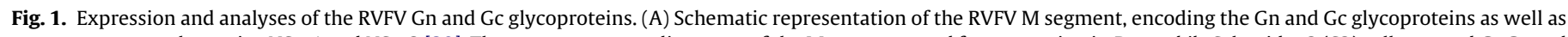

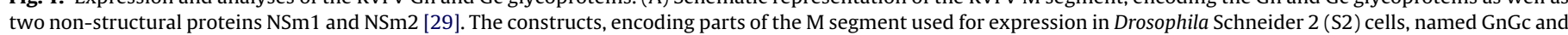

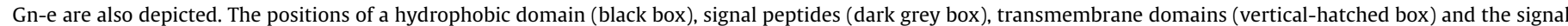

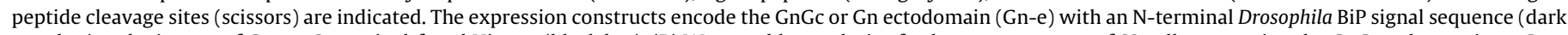

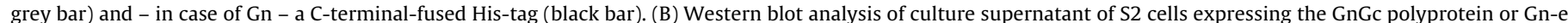

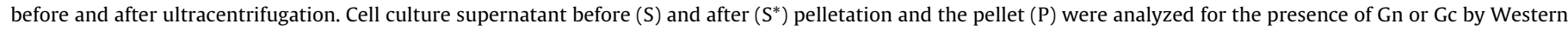

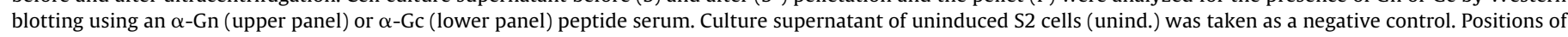

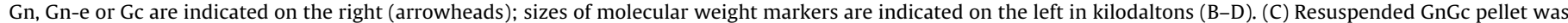

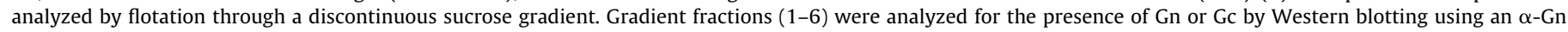

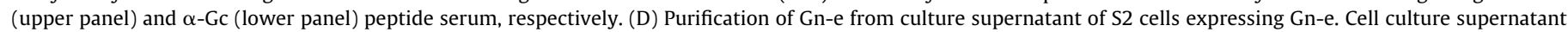
before (S) and after ( $\left.\mathrm{S}^{*}\right)$ His-tag affinity purification and purified $\mathrm{Gn}$-e (Pu) were analyzed by Western blotting using the $\alpha$-Gn peptide serum. 


\subsection{Statistical analyses}

Statistical analyses were performed with the Kruskal-Wallis one-way analysis of variance (ANOVA) or two-way ANOVA Bonferroni post-test using GraphPad Prism version 5.00 for Windows (GraphPad Software, San Diego, CA, USA). Statistical differences with $p$-values $<0.05$ were considered significant.

\section{Results}

\subsection{Expression of RVFV glycoproteins in Drosophila cells}

The Drosophila expression system (Invitrogen ${ }^{\mathrm{TM}}$ ) is an attractive system for expression of secretable proteins. It allows inducible expression and secretion of soluble glycoproteins under non-lytic conditions and in serum-free medium. In order to produce RVFV VLPs we generated a stable Schneider 2 (S2) cell line allowing the inducible expression of the GnGc polyprotein (Fig. 1A). Upon induction both glycoproteins could be detected in the cell culture supernatant by Western blotting (Fig. 1B). Consistent with their being secreted in the form of VLPs, Gn and Gc co-sedimented through a $20 \%(\mathrm{w} / \mathrm{w})$ sucrose cushion (Fig. 1B) and subsequently co-floated in a discontinuous sucrose gradient (Fig. 1C). The Gn and Gc proteins accumulated at a buoyant density of $\sim 1.14 \mathrm{~g} / \mathrm{cm}^{3}$ which is close to the buoyant density of RVFV of $1.16-1.18 \mathrm{~g} / \mathrm{cm}^{3}[46,47]$. The observations indicate that expression of the RVFV GnGc polyprotein in insect cells results in the formation and secretion of VLPs. The morphology of the generated VLPs analysed by transmission electron microscopy indicated a circular or donut shaped morphology with spiky surface protrusions (Fig. 2).

To also produce the $\mathrm{Gn}$ protein we separately generated a stable cell line expressing the Gn ectodomain (Gn-e, Fig. 1A). Gn-e could readily be detected in the culture supernatant but, as expected for a soluble protein and unlike the VLPs, could not be concentrated by ultracentrifugation (Fig. 1B). Gn-e was successfully purified from the cell culture supernatant using nickel chelate beads via its Cterminal-fused 6xHis-tag (Fig. 1D).

\subsection{Immunogenicity of RVFV VLPs and the Gn ectodomain}

To investigate and compare the immunogenic properties of the RVFV GnGc VLPs and of the Gn-e protein, groups of 10 mice were immunized via the intraperitoneal route and boosted three weeks later. Sucrose-cushion concentrated VLPs and affinity-purified Gne were each formulated in Stimune adjuvant. Stimune, previously known as specol [48], is a water-in-mineral oil emulsion which strongly promotes the induction of antibodies with a low incidence of site reactivity [49]. Another 10 animals served as an adjuvant control group and were administered Stimune only. Since VLPs are regarded morphological representatives of the authentic viral particles and should therefore be able to stimulate a strong immune response in the absence of adjuvant $[17,30,50]$ we additionally included a group of mice that were vaccinated with unadjuvanted VLPs. All formulations were applied at a dose of $10 \mu \mathrm{g}$ in $500 \mu \mathrm{l}$ per mouse. Unfortunately, of the Stimune control group 4 mice were lost due to an experimental handling error. A fifth group of 10 non-vaccinated mice was therefore added as an additional challenge control group. In none of the groups clinical symptoms were observed before challenge.

Sera of mice were collected weekly until the day of challenge. After challenge, deceased mice were bled when possible and surviving mice were bled before euthanasia via orbital puncture. Sera were analyzed for the presence of antibodies against Gn and/or Gc by enzyme-linked immunosorbent assay (ELISA, Fig. 3A), immunoperoxidase monolayer assay (IPMA, Fig. 3B) and virus neutralization tests (VNT, Fig. 3C). The GST-GnGc peptide ELISA was developed to specifically detect antibodies against a linear epitope in Gn and one in Gc. Mice vaccinated with VLPs (with or without adjuvant) seroconverted already after the first
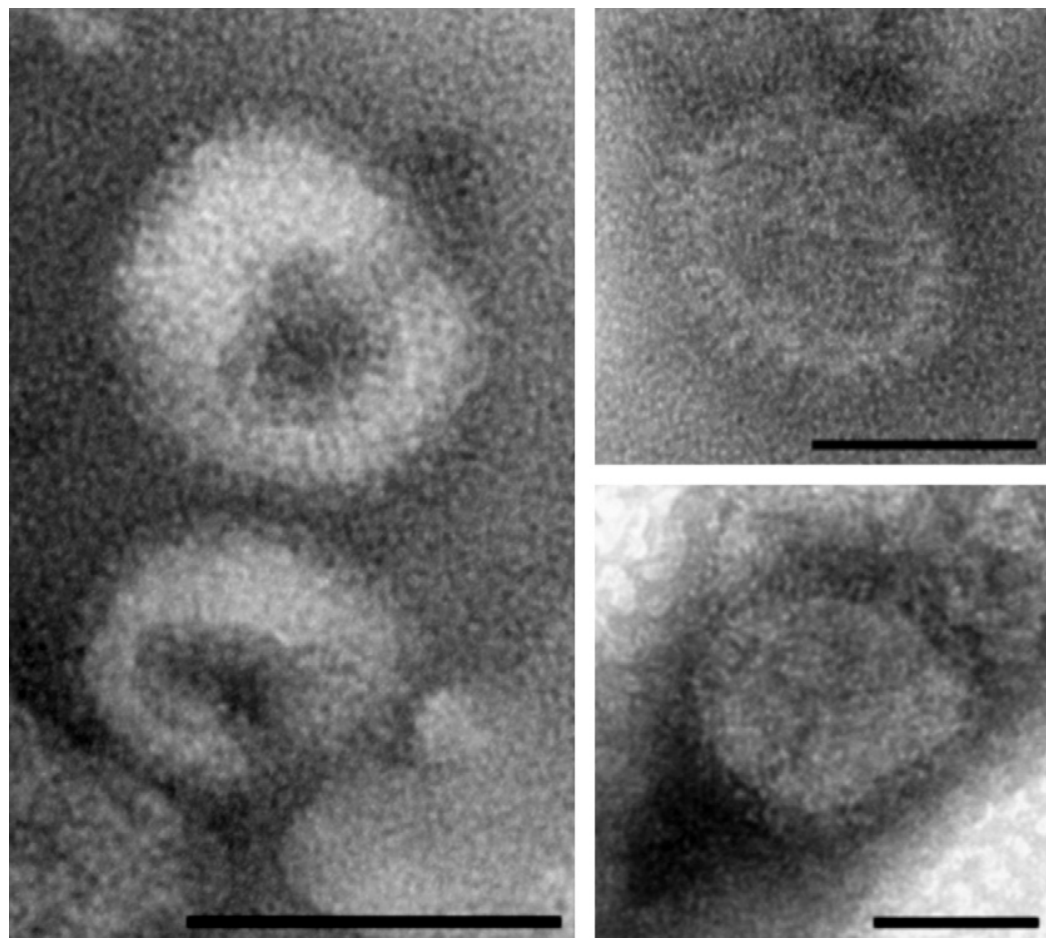

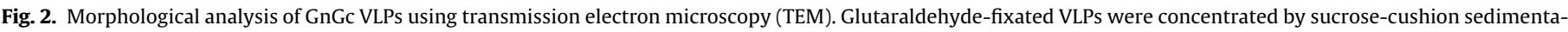

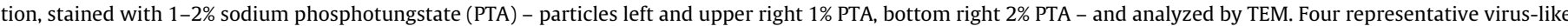
particles are depicted showing spiky structures on their surface. Scale bar on the left represents $100 \mathrm{~nm}$, both scale bars on the right represent $50 \mathrm{~nm}$. 

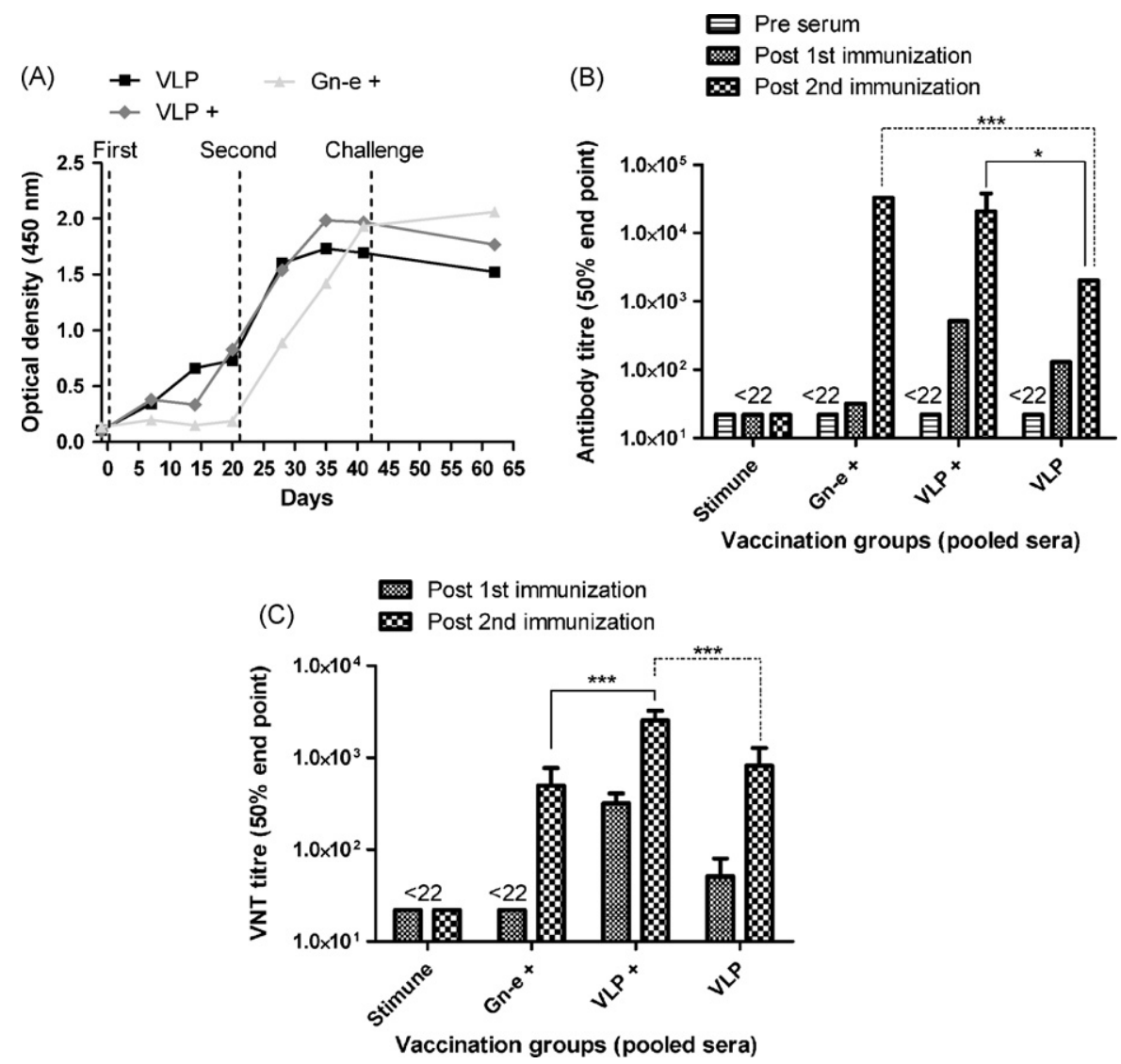

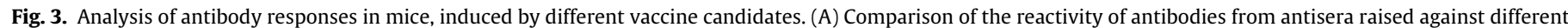

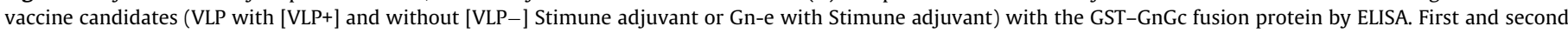

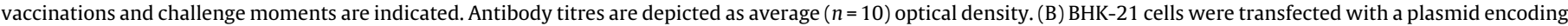

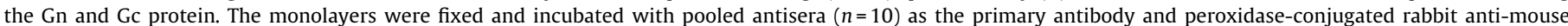

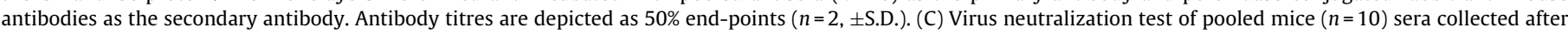

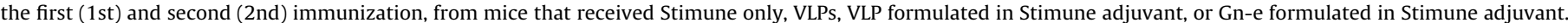
The results are depicted as $50 \%$ end-point titres $\left(n=4, \pm\right.$ S.D.). Titres were calculated using the Spearman-Kärber method. ${ }^{*} p<0.05$; ${ }^{* * *} p<0.001$.

vaccination, whereas seroconversion induced by Gn-e required two vaccinations (Fig. 3A). This result demonstrates that the GST-GnGc peptide ELISA is suitable to detect differences in antibody responses induced by the different vaccines. In view of the inherent limitations of this peptide ELISA, we also used IPMAs to compare GnGc antibody levels induced by the different vaccine candidates. The Stimune formulated VLP $(p<0.05)$ and Gn-e $(p<0.001)$ vaccines elicited significantly higher antibody titres after the second immunization when compared with the non-adjuvanted VLPs (Fig. 3B). Since the GST-GnGc ELISA results were confirmed by IPMA, we consider the GnGc peptide ELISA a reliable tool to compare antibody responses induced by glycoprotein-based RVFV vaccine candidates.

To determine whether the sera obtained after the first and second vaccination were able to neutralize the virus in vitro, virus neutralization tests were performed. Neither a negative control serum (data not shown) nor a pooled serum from Stimune vaccinated mice was able to neutralize the virus (Fig. 3C). Sera obtained from mice vaccinated with VLPs, with or without adjuvant, obtained after the primary vaccination were able to neutralize the virus, and the level of these antibodies increased after the secondary vaccination. In contrast, the induction of neutralizing antibodies by Gn-e required two vaccinations (Fig. 3C). The neutralizing antibody levels obtained after vaccination with Stimune adjuvanted VLPs were significantly higher than those obtained after vaccination with non-adjuvanted VLPs $(p<0.001)$ or Gn-e $(p<0.001)$ (Fig. 3C). In conclusion, Gn-e induces the highest over- all antibody titres (Fig. 3A and B), though the antibodies induced by VLPs are more potent in neutralizing RVFV. Secondly, Stimune adjuvanted VLPs induce significantly higher levels of neutralizing antibodies in mice than adjuvanted Gn-e or non-adjuvanted VLPs (Fig. 3C).

\subsection{Protection against a lethal challenge}

Three weeks after the second immunization mice were challenged via the intraperitoneal route with a lethal dose $\left(10^{2.7} \mathrm{TCID}_{50}\right)$ of the RVFV strain M35/74. The lethal dose was previously determined by two independent dose-titration experiments (Antonis A.F. et al., manuscript in preparation). All mice were monitored weekly for weight-loss and daily for clinical signs.

The adjuvant-only and non-vaccinated groups showed $83 \%$ and $100 \%$ mortality, respectively (Fig. 4A). In contrast, all mice immunized with RVFV antigens survived, regardless of the antigen composition and whether or not adjuvant was used. Moreover, the body weights of these mice were stable and the mice did not develop any clinical signs throughout the experiment (Fig. 4B and C). In contrast, the non-vaccinated mice developed severe clinical signs (Fig. 4C), which resulted in $100 \%$ mortality within 4 days. Interestingly, the Stimune control group showed delayed symptoms. Twelve days after challenge, five out of the total of six mice from this group had succumbed to the infection, whereas the sixth mouse was negative in all our serological assays. However, in this mouse, viral RNA was detected in both the liver and the 

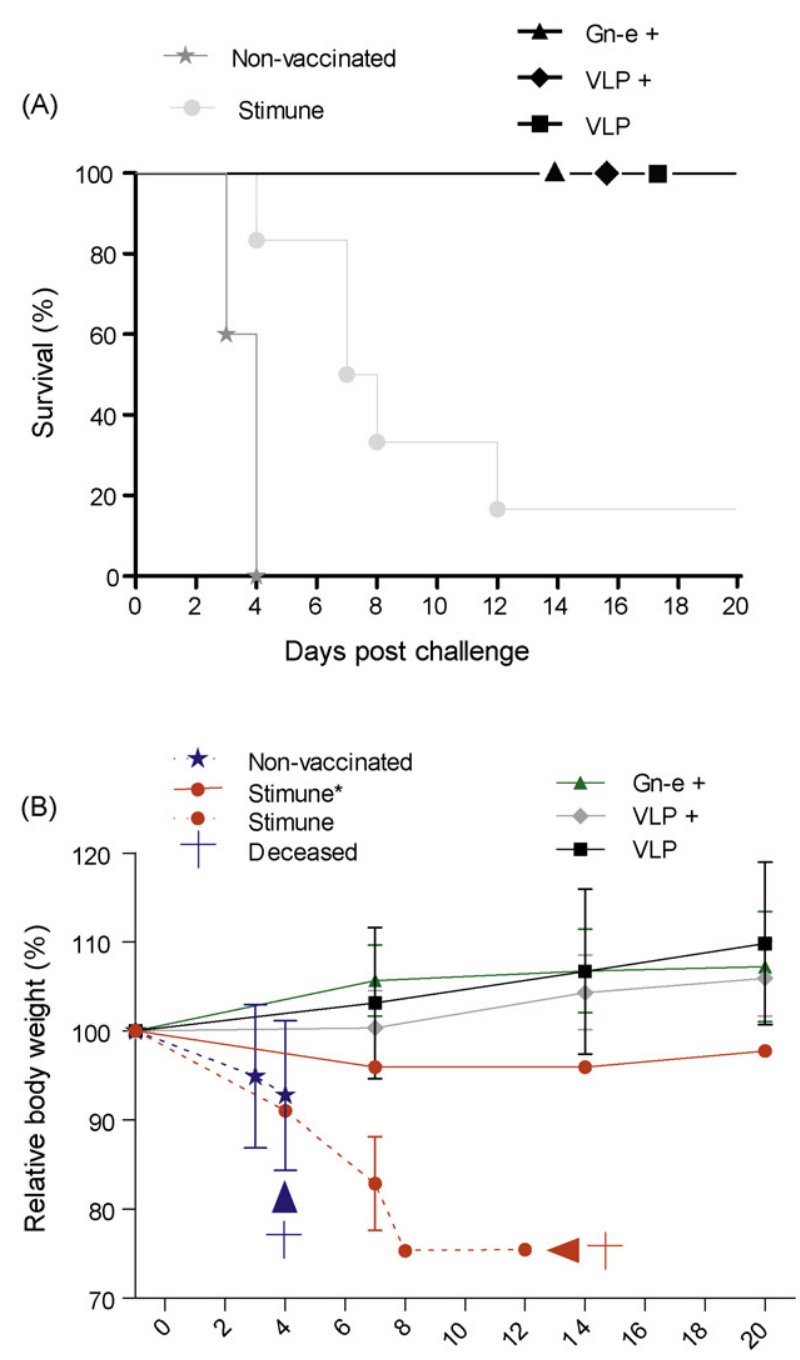

Days post challenge
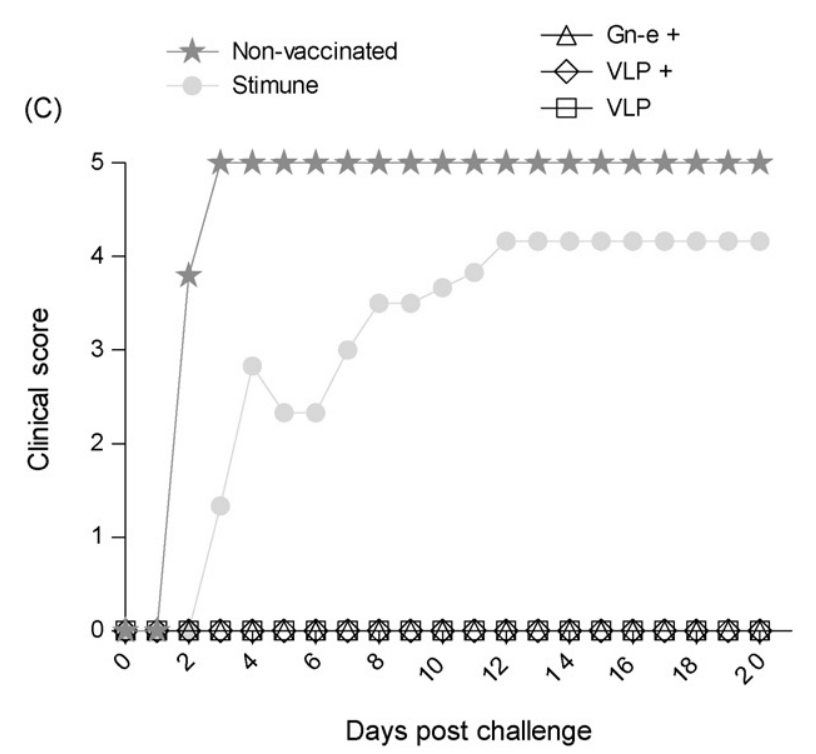

Fig. 4. Vaccination with RVFV VLPs or the Gn ectodomain protects mice against lethal RVFV infection. Groups of mice $(n=10)$ were either non-vaccinated or vaccinated twice with adjuvant only (Stimune; $n=6$ ), $10 \mu \mathrm{g}$ VLPs with (VLP+; $n=10$ ) or without (VLP; $n=10$ ) Stimune adjuvant, or $10 \mu$ g adjuvanted Gn-e (Gn-e+; $n=10$ ). Mice were challenged with $10^{2.7} \mathrm{TCID}_{50}$ of RVFV strain M35/74 via the intraperitoneal route. Mice were monitored daily, until 20 days post-challenge, for
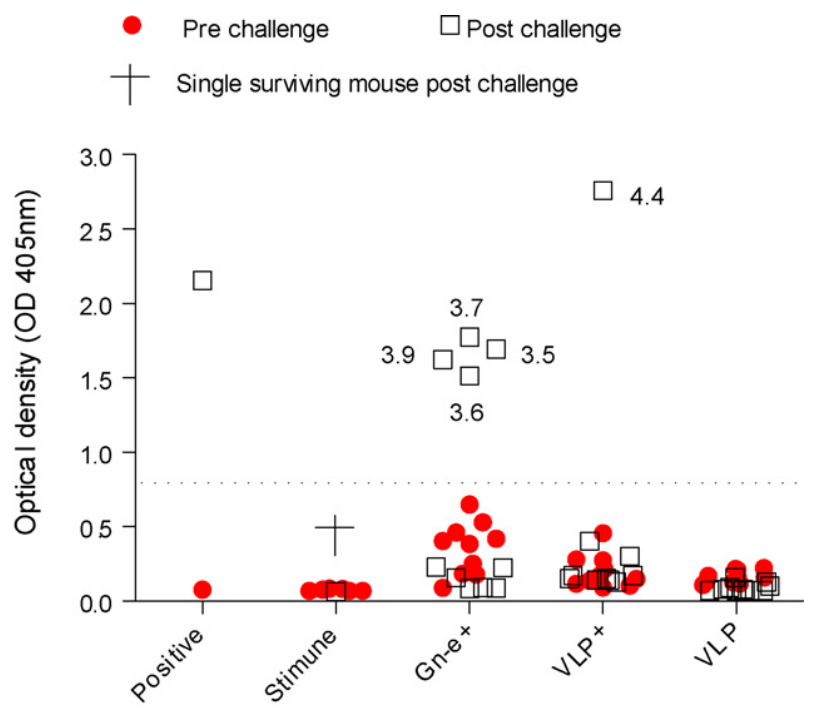

Fig. 5. Detection of N-antibodies in mice sera pre- and post-RVFV challenges. The pre- and post-challenge sera of mice vaccinated with Stimune only (Stimune), adjuvanted Gn-e or VLP (Gn-e+ and VLP+) or non-adjuvanted VLP (VLP), were screened for the presence of antibodies against the nucleoprotein using an indirect recombinant N-ELISA $(n=2)$ [42]. Serum from a RVFV infected mouse was used as a reference control (positive). The dotted line represents the cut-off value, which was arbitrarily set at 0.80 . Numbers of some individual mice are depicted in the graph.

brain (Fig. 6). The delayed disease in mice inoculated with Stimune might be explained by unspecific immune modulatory effects [51,52].

Since our RVFV vaccines are only comprised of the viral envelope glycoproteins, the detection of antibodies against the nucleocapsid protein in sera after challenge would be a good indicator of viral replication. To further verify if vaccination suppressed virus replication, we screened sera for the presence of anti-N antibodies using a commercially available recombinant N-ELISA [42] (Fig. 5) and performed quantitative real-time reverse-transcriptase PCR on liver and brain samples to detect viral RNA (Fig. 6). The postchallenge sera from four out of ten Gn-e vaccinated mice did show some antibodies against N (Fig. 5) and in two liver samples and one brain sample viral RNA was detected (Fig. 6). This indicates that despite these mice survived RVFV infection, some viral replication had occurred. In the group vaccinated with adjuvanted VLPs, only one animal was positive in the recN-ELISA, whereas none of the mice of the non-adjuvanted VLP group had detectable levels of $\mathrm{N}$-antibodies. In five of the ten mice that were vaccinated with nonadjuvanted VLPs, viral RNA was detected in liver samples (Fig. 6A). Intriguingly, with one exception (mouse \#3.5), vaccinated mice which contained viral RNA in the liver or the brain did not seroconvert for antibodies against the N protein (Figs. 5 and 6) and vice-versa - mice positive in the recN-ELISA did not have detectable levels of viral RNA in neither the liver nor the brain. Experiments are in progress to further elucidate these findings.

In conclusion, our findings suggest that all vaccine candidates provide full protection against a lethal RVFV challenge, and that vaccination with adjuvanted VLPs even results in sterile immunity in $90 \%$ of the mice.

mortality (A) and clinical scores (C, $n=6$ or $n=10$ ) and weekly for weight (B, $n=6$ or $n=10 \pm$ S.D.). The body weights of the only survivor of the Stimune-vaccinated control group are depicted separately (Stimune*). Number coding related to the clinical scores $(\mathrm{C})$ are 0 = normal healthy; 1 = active, hairs raised; 2 = less active, hairs raised; 3 = less active, hairs raised, accelerated respiration, coiled; $4=$ less active, hairs raised, accelerated respiration, hunchback like posture. Mouse fails to roll from posterior to anterior, when place on its back; 5 = mouse deceased. 

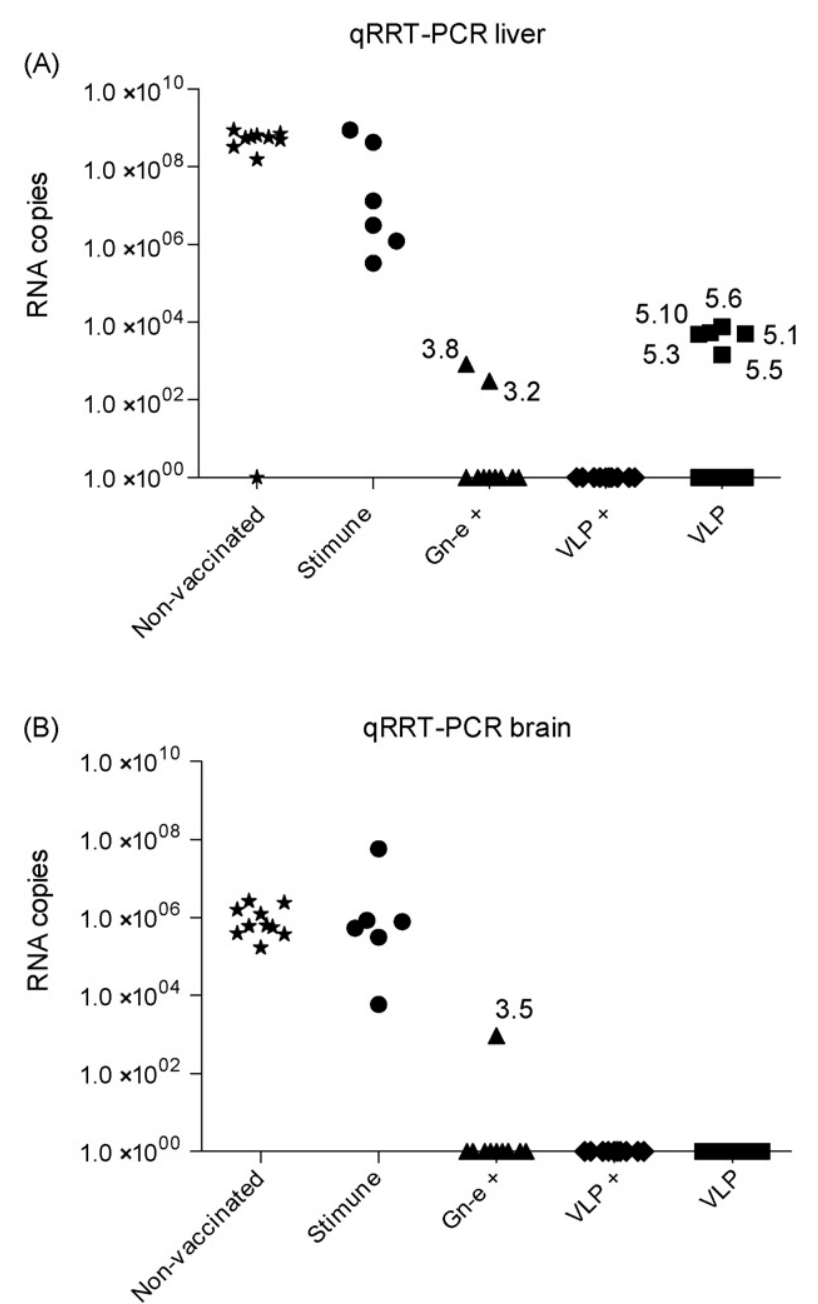

Fig. 6. Detection of viral RNA in liver and brain samples by quantitative real-time reverse-transcriptase PCR (qRRT-PCR). The non-vaccinated mice, mice inoculated with Stimune adjuvant, mice vaccinated with adjuvanted Gn ectodomain or VLPs with or without adjuvant were challenged with RVFV. The livers (A) and brains (B) of the deceased or euthanized mice were screened for the presence of viral RNA using qRRT-PCR. Numbers of some individual mice are depicted in the graph.

\section{Discussion}

RVFV is a mosquito-borne virus causing disease in livestock and humans. Although the virus has so far been confined to the African continent and the Arabian peninsula, global warming and globalization increase the risk of virus migration towards new virgin soils [53]. Hence, there is an urgent need for a save and effective vaccine that is applicable to both humans and livestock. Here we report the successful production of two vaccine candidates against RVF based on the RVFV surface glycoproteins. Both vaccine candidates fully protected mice from a lethal challenge with RVFV.

Until recently [18], RVFV VLPs were successfully produced, using alternative expression systems, only when the nucleocapsid protein was included. Specifically, VLPs were obtained by coexpression of GnGc with the nucleocapsid protein using the baculovirus insect expression system [33] or in combination with a mini-replicon system consisting of the nucleocapsid protein, the polymerase protein and a mini-genome RNA using a mammalian expression system [32]. Our nucleocapsid protein-independent assembly of VLPs is consistent with recent work of Mandell et al. [18], in which expression of the Gn and Gc proteins was shown to be sufficient for the formation and secretion of VLPs [18]. In the work of Mandell et al., three vaccinations of mice with VLPs containing only Gn and Gc pro- vided protection in only $19 \%$ of the animals, whereas in the current work, two vaccinations with VLPs lacking the $\mathrm{N}$ protein resulted in $100 \%$ protection. Moreover, when these VLPs were formulated in Stimune adjuvant, sterile immunity was even obtained in nine out of ten mice.

Due to the increased international trade of animals and concomitant surveillance, the development of DIVA vaccines is of great importance. The absence of the nucleocapsid protein in our vaccine candidates will facilitate the development of a DIVA vaccine for livestock that can be accompanied by the recN ELISA [42]. The $\mathrm{N}$ protein of RVFV is highly immunogenic, inducing antibodies already within the first days after infection [54] and is therefore an ideal target in diagnostic ELISAs [42]. Surprisingly, Naslund et al. [17] observed that mice vaccinated with VLPs containing the nucleocapsid protein could be serologically distinguished from infected animals using an $\mathrm{N}$-based ELISA. Apparently, the antibody response against the $\mathrm{N}$ protein induced by these VLPs was sufficiently low to enable this differentiation. Yet, use of VLPs that lack the nucleocapsid protein, such as those developed in the current work, will minimize the chances of obtaining false-positive results in field diagnostics.

Based on its limited but significant similarity with the alphavirus E2 glycoprotein, it has been suggested that the Gn protein of Bunyaviruses might function as the receptor binding protein [55] and would therefore be a good target antigen for inducing virus neutralizing antibodies. Indeed, Gn is known to contain neutralizing epitopes [56,57]. Accordingly, protection against RVFV challenge based on Gn could be achieved by inoculation of animals with bacterial lysates or baculovirus-infected eukaryotic cells containing only the Gn protein [16,21], or by alphavirus vectors expressing the Gn ectodomain [58]. We demonstrate that immunization with soluble adjuvanted $\mathrm{Gn}$ ectodomain provides full protection against RVFV. Of note, the antibody titres induced by the Gn ectodomain (i.e. Gn-e) were equal to those induced by VLPs formulated in Stimune adjuvant and significantly higher then those induced by VLPs only $(p<0.001)$. It is important to stress, however, that neutralizing antibodies were readily obtained after a single vaccination with VLPs, whereas induction of these antibodies by Gn-e required two vaccinations. This observation might be explained by the repetitive arrangement of the Gn and Gc antigens on the VLP surface allowing efficient cross-linking of the immunoglobulin receptors on B cells which can greatly facilitate B-cell activation [31].

The absence of clinical signs, seroconversion and our inability to detect viral genome in livers and brains in $90 \%$ of the mice vaccinated with adjuvanted VLPs suggest that sterile immunity was obtained in these animals. Although no clinical signs were observed in mice vaccinated with VLPs without adjuvant, low levels of viral RNA were detected in $50 \%$ of the livers. Apparently, some viral replication occurred in these animals.

Although RVFV has the potential to cause severe disease in humans, no vaccine or antiviral agent for human application is available. Efforts are being made to produce live attenuated vaccines for use in humans [29]. The safety of such vaccines has to be thoroughly tested, however. Such safety concerns do not apply to subunit vaccines as those reported here. The Drosophila S2 expression system, used to produce the VLPs and the Gn ectodomain in the current work, offers the additional advantage of serum-free production and has been used previously to produce secreted forms of native-like glycoproteins in large amounts for vaccine applications $[59,60]$. In addition, the recombinant subunit approach allows for convenient antigen affinity purification by appending a purification tag, which is beneficial especially for human vaccine development.

In summary, we report here the efficient production of RVFV VLPs and the Gn ectodomain using a robust insect expression system. The vaccine candidates provide full protection against a lethal RVFV challenge. Additional studies should be performed to estab- 
lish the DIVA property and minimal protective dose of these vaccine candidates in sheep. The necessity of repeated vaccination should also be evaluated. It is furthermore important to study contribution of humoral and cellular immunity and the durability of protection. Our study demonstrates the potential of a RVFV subunit vaccine, either in the form of VLPs or soluble protein.

\section{Conflict of interest}

None.

\section{Acknowledgments}

We would like to thank the staff of our animal facility (Central Veterinary Institute of Wageningen UR, Lelystad, The Netherlands). We would like to thank Willem Bartelink for his excellent technical help as well as Susanna Commandeur and Ewoud Compeer (Utrecht University, The Netherlands). We thank George Posthuma of the Cell Microscopy Centre (Department of Cell Biology, UMCU, The Netherlands) for his technical assistance with the electron microscopic analyses. We would like to thank Prof. Dr. Janusz Paweska of the National Institute for Communicable Diseases (Johannesburg, South Africa) and Dr. Christiaan Potgieter of the Agricultural Research Council-Onderstepoort Veterinary Institute (Onderstepoort, South Africa) for sharing their experiences on RVFV and providing us with the M35/74 virus strain. This work was commissioned and financed by the Dutch Ministry of Agriculture, Nature and Food Quality, project code KB-08-003-001.36.

\section{References}

[1] CDC. Outbreak of Rift Valley fever - Yemen, August-October 2000. Morb Mortal Wkly Rep 2000;49(Dec 1 (47)):1065-6.

[2] Weiss K. Rift Valley fever: a review. Bull Epizootic Dis Africa 1957;5:413-58.

[3] Mundel B, Gear J. Rift valley fever. I. The occurrence of human cases in Johannesburg. S Afr Med J 1951;25(November 3 (44)):797-800.

[4] McIntosh BM, Russell D, dos Santos I, Gear JH. Rift Valley fever in humans in South Africa. S Afr Med J 1980;58(November 15 (20)):803-6.

[5] CDC. Rift Valley fever outbreak - Kenya, November 2006-January 2007. Morb Mortal Wkly Rep 2007;56(February 2 (4)):73-6.

[6] WHO. Outbreaks of Rift Valley fever in Kenya, Somalia and United Republic of Tanzania. December 2006-April 2007. Wkly Epidemiol Rec 2007;82(May 18 (20)):169-78.

[7] WHO. Outbreak news. Rift Valley fever, Sudan-update. Wkly Epidemiol Rec 2007;82(November 30 (48)):417-8.

[8] WHO. Outbreak news. Rift Valley fever, Madagascar. Wkly Epidemiol Rec 2008;83(May 21 (8)):157.

[9] Rabinowitz PGZ, Chudnov D, Wilcox M, Odofin L, Liu A, Dein J. Animals as sentinels of bioterrorism agents. Emerg Infect Dis 2006;12(May (4)):647-52.

[10] Borio LIT, Peters CJ, Schmaljohn AL, Hughes JM, Jahrling PB, et al. Hemorrhagic fever viruses as biological weapons. JAMA 2002;287(May (18)):2391-405.

[11] Schmaljohn CSHJ. Bunyaviridae: the viruses and their replication. In: Knipe DMHP, editor. Fields Virology. Philadelphia: Lippincott Williams \& Wilkins; 2001. p. 695-714.

[12] Gerrard SR, Nichol ST. Synthesis, proteolytic processing and complex formation of N-terminally nested precursor proteins of the Rift Valley fever virus glycoproteins. Virology 2007;357(January 20 (2)):124-33.

[13] Huiskonen JT, Overby AK, Weber F, Grunewald K. Electron cryo-microscopy and single-particle averaging of Rift Valley fever virus: evidence for GN-GC glycoprotein heterodimers. J Virol 2009;83(April (8)):3762-9.

[14] Gerrard SR, Nichol ST. Characterization of the Golgi retention motif of Rift Valley fever virus $G(N)$ glycoprotein. J Virol 2002;76(December (23)):12200-10.

[15] Freiberg AN, Sherman MB, Morais MC, Holbrook MR, Watowich SJ. Threedimensional organization of Rift Valley fever virus revealed by cryoelectron tomography. J Virol 2008;82(November (21)):10341-8.

[16] Schmaljohn CS, Parker MD, Ennis WH, Dalrymple JM, Collett MS, Suzich JA, et al. Baculovirus expression of the M genome segment of Rift Valley fever virus and examination of antigenic and immunogenic properties of the expressed proteins. Virology 1989;170(May 1):184-92.

[17] Naslund J, Lagerqvist N, Habjan M, Lundkvist A, Evander M, Ahlm C, et al. Vaccination with virus-like particles protects mice from lethal infection of Rift Valley fever virus. Virology 2009;385(March 15 (2)):409-15.

[18] Mandell RB, Koukuntla R, Mogler LJ, Carzoli AK, Freiberg AN, Holbrook MR, et al. A replication-incompetent Rift Valley fever vaccine: chimeric virus-like particles protect mice and rats against lethal challenge. Virology 2009;(November 23) [Epub ahead of print].
[19] Spik K, Shurtleff A, McElroy AK, Guttieri MC, Hooper JW, SchmalJohn C. Immunogenicity of combination DNA vaccines for Rift Valley fever virus, tickborne encephalitis virus, Hantaan virus, and Crimean Congo hemorrhagic fever virus. Vaccine 2006;24(May 22 (21)):4657-66.

[20] Lagerqvist N, Naslund J, Lundkvist A, Bouloy M, Ahlm C, Bucht G. Characterisation of immune responses and protective efficacy in mice after immunisation with Rift Valley Fever virus cDNA constructs. Virol J 2009;6:6.

[21] Wallace DB, Ellis CE, Espach A, Smith SJ, Greyling RR, Viljoen GJ. Protective immune responses induced by different recombinant vaccine regimes to Rift Valley fever. Vaccine 2006;24(November 30 (49-50)):7181-9.

[22] Heise MT, Whitmore A, Thompson J, Parsons M, Grobbelaar AA, Kemp A, et al. An alphavirus replicon-derived candidate vaccine against Rift Valley fever virus. Epidemiol Infect 2009;137(September (9)):1309-18.

[23] Smithburn KC. Rift Valley fever; the neurotropic adaptation of the virus and the experimental use of this modified virus as a vaccine. Br J Exp Pathol 1949;30(February (1)):1-16.

[24] Caplen H, Peters CJ, Bishop DH. Mutagen-directed attenuation of Rift Valley fever virus as a method for vaccine development. J Gen Virol 1985;66(October):2271-7.

[25] Muller R, Saluzzo JF, Lopez N, Dreier T, Turell M, Smith J, et al. Characterization of clone 13, a naturally attenuated avirulent isolate of Rift Valley fever virus, which is altered in the small segment. Am J Trop Med Hyg 1995;53(October (4)):405-11.

[26] Bird BH, Albarino CG, Hartman AL, Erickson BR, Ksiazek TG, Nichol ST. Rift valley fever virus lacking the NSs and NSm genes is highly attenuated, confers protective immunity from virulent virus challenge, and allows for differential identification of infected and vaccinated animals. J Virol 2008;82(March (6)):2681-91.

[27] Pittman PR. Safety and immunogenicity of live-attenuated MP-12 Rift Valley fever vaccine (ZH548, MP-12, TSI-GSD-223 Lot 7-2-88) in humans, and genetic characterization of virus isolates recovered from the blood of vaccinated volunteers: a phase II study. Available from: http://clinicaltrials.gov/ ct2/show/NCT00415051.

[28] Pittman PR, Liu CT, Cannon TL, Makuch RS, Mangiafico JA, Gibbs PH, et al. Immunogenicity of an inactivated Rift Valley fever vaccine in humans: a 12year experience. Vaccine 1999;18(August 20 (1-2)):181-9.

[29] Bouloy M, Flick R. Reverse genetics technology for Rift Valley fever virus: current and future applications for the development of therapeutics and vaccines. 2009;84(November (2)):101-118 [Epub 2009 August 12].

[30] Roy P, Noad R. Virus-like particles as a vaccine delivery system: myths and facts. Hum Vaccine 2008;4(January-February (1)):5-12.

[31] Bachmann MF, Zinkernagel RM. Neutralizing antiviral B cell responses. Annu Rev Immunol 1997;15:235-70.

[32] Habjan M, Penski N, Wagner V, Spiegel M, Overby AK, Kochs G, et al. Efficient production of Rift Valley fever virus-like particles: the antiviral protein MxA can inhibit primary transcription of bunyaviruses. Virology 2009;385(March $15(2)): 400-8$

[33] Liu L, Celma CC, Roy P. Rift Valley fever virus structural proteins: expression, characterization and assembly of recombinant proteins. Virol J 2008;5:82.

[34] Betenbaugh M, Yu M, Kuehl K, White J, Pennock D, Spik K, et al. Nucleocapsidand virus-like particles assemble in cells infected with recombinant baculoviruses or vaccinia viruses expressing the $M$ and the $S$ segments of Hantaan virus. Virus Res 1995;38(October (2-3)):111-24.

[35] Overby AK, Popov V, Neve EP, Pettersson RF. Generation and analysis of infectious virus-like particles of uukuniemi virus (bunyaviridae): a useful system for studying bunyaviral packaging and budding. J Virol 2006;80(November (21)):10428-35

[36] Niwa H, Yamamura K, Miyazaki J. Efficient selection for high-expression transfectants with a novel eukaryotic vector. Gene 1991;108(December 15 (2)):193-9.

[37] Filone CM, Heise M, Doms RW, Bertolotti-Ciarlet A. Development and characterization of a Rift Valley fever virus cell-cell fusion assay using alphavirus replicon vectors. Virology 2006;356(December 5-20 (1-2)):155-64.

[38] Schneider I. Cell lines derived from late embryonic stages of Drosophila melanogaster. J Embryol Exp Morphol 1972;27(April (2)):353-65.

[39] Johansen H, van der Straten A, Sweet R, Otto E, Maroni G, Rosenberg M. Regulated expression at high copy number allows production of a growth-inhibitory oncogene product in Drosophila Schneider cells. Genes Dev 1989;3(June (6)):882-9.

[40] Bosch BJ, van der Zee R, de Haan CA, Rottier PJ. The coronavirus spike protein is a class I virus fusion protein: structural and functional characterization of the fusion core complex. J Virol 2003;77(August (16)):8801-11.

[41] Leenaars PP, Hendriksen CF, Koedam MA, Claassen I, Claassen E. Comparison of adjuvants for immune potentiating properties and side effects in mice. Vet Immunol Immunopathol 1995;48(September (1-2)):123-38.

[42] Paweska JT, van Vuren PJ, Kemp A, Buss P, Bengis RG, Gakuya F, et al. Recombinant nucleocapsid-based ELISA for detection of IgG antibody to Rift Valley fever virus in African buffalo. Vet Microbiol 2008;127(February 5 (1-2)): 21-8.

[43] Kärber G. Beitrag zur kollektiven Behandlung pharmakologischer Reihenversuche. Arch Exp Path Pharmak 1931;162:480-3.

[44] Spearman C. The method of "right and wrong cases" ("constant stimuli") without Gauss's formulae. Br J Psychol 1908;2:227-42.

[45] Drosten C, Gottig S, Schilling S, Asper M, Panning M, Schmitz H, et al. Rapid detection and quantification of RNA of Ebola and Marburg viruses, Lassa virus, Crimean-Congo hemorrhagic fever virus. Rift Valley fever virus, dengue virus, 
and yellow fever virus by real-time reverse transcription-PCR. J Clin Microbiol 2002;40(July (7)):2323-30.

[46] Gonzalez-Scarano F, Nathanson N. Bunyaviridae. In: Fields BN, Knipe DM, Howley PM, et al., editors. Fields virology. Philadelphia: Raven Publishers; 1996. p. 1476.

[47] Ikegami T, Won S, Peters CJ, Makino S. Rift Valley fever virus NSs mRNA is transcribed from an incoming anti-viral-sense S RNA segment. J Virol 2005;79(September (18)):12106-11.

[48] Bokhout BA, Bianchi AT, van der Heijden PJ, Scholten JW, Stok W. The influence of a water-in-oil emulsion on humoral immunity. Comp Immunol Microbiol Infect Dis 1986;9(2-3):161-8.

[49] Beck I, Gerlach H, Burkhardt E, Kaleta EF. Investigation of several selected adjuvants regarding their efficacy and side effects for the production of a vaccine for parakeets to prevent a disease caused by a paramyxovirus type 3 . Vaccine 2003;21(February 14 (9-10)):1006-22.

[50] Zhang LF, Zhou J, Chen S, Cai LL, Bao QY,Zheng FY, et al. HPV6b virus like particles are potent immunogens without adjuvant in man. Vaccine 2000;18(January 6 $(11-12)): 1051-8$

[51] Edelman R. Vaccine adjuvants. Rev Infect Dis 1980;2(May-June (3)): 370-83.

[52] Barrios C, Brandt C, Berney M, Lambert PH, Siegrist CA. Partial correction of the TH2/TH1 imbalance in neonatal murine responses to vaccine antigens through selective adjuvant effects. Eur J Immunol 1996;26(November (11)): 2666-70.
[53] Alley R, Berntsen T, Bindoff NL, Chen Z, Chidthaisong A, Friedlingstein P, et al. IPCC WGI fourth assessment report: climate change 2007: the physical science basis: WMO and UNEP; 2007.

[54] Swanepoel R, Struthers JK, Erasmus MJ, Shepherd SP, McGillivray GM, Erasmus BJ, et al. Comparison of techniques for demonstrating antibodies to Rift Valley fever virus. J Hyg (Lond) 1986;97(October (2)):317-29.

[55] Garry CE, Garry RF. Proteomics computational analyses suggest that the carboxyl terminal glycoproteins of Bunyaviruses are class II viral fusion protein (beta-penetrenes). Theor Biol Med Model 2004;1:10.

[56] Besselaar TG, Blackburn NK. Topological mapping of antigenic sites on the Rift Valley fever virus envelope glycoproteins using monoclonal antibodies. Arch Virol 1991;121(1-4):111-24.

[57] Besselaar TG, Blackburn NK. The synergistic neutralization of Rift Valley fever virus by monoclonal antibodies to the envelope glycoproteins. Arch Virol 1992;125(1-4):239-50.

[58] Gorchakov R, Volkova E, Yun N, Petrakova O, Linde NS, Paessler S, et al. Comparative analysis of the alphavirus-based vectors expressing Rift Valley fever virus glycoproteins. Virology 2007;366(1 (September 15)):212-25

[59] Lieberman MM, Clements DE, Ogata S, Wang G, Corpuz G, Wong T, et al. Preparation and immunogenic properties of a recombinant West Nile subunit vaccine. Vaccine 2007;25(January 5 (3)):414-23.

[60] Lieberman MM, Nerurkar VR, Luo H, Cropp B, Carrion Jr R, de la Garza M, et al. Immunogenicity and protective efficacy of a recombinant subunit West Nile virus vaccine in rhesus monkeys. Clin Vaccine Immunol 2009;29(July). 